\title{
Review: optimal shock and vibration isolation
}

\author{
D.V. Balandin ${ }^{\mathrm{a}}$, N.N. Bolotnik ${ }^{\mathrm{b}}$ and \\ W.D. Pilkey ${ }^{\mathrm{c}}$ \\ ${ }^{a}$ Research Institute for Applied Mathematics and \\ Cybernetics, Nizhny Novgorod State University, \\ 10 Uljanova Str., Nizhny Novgorod 603005, Russia \\ ${ }^{\mathrm{b}}$ Institute for Problems in Mechanics, Russian \\ Academy of Sciences, 101 Prospect Vernadskogo, \\ Moscow 117526, Russia \\ ${ }^{\mathrm{c}}$ Department of Mechanical, Aerospace, and Nuclear \\ Engineering, Thornton Hall, University of Virginia, \\ Charlottesville, VA 22903-2442, USA
}

Received 30 March 1997

Revised 26 April 1998

This is a review of the investigations into the field of optimum shock and vibration isolation, including the mathematical foundations of both optimal open-loop and optimal feedback isolation systems. This survey covers the literature from the initial studies to the present.

Keywords: Shock isolation, impact protection, vibration isolation, optimal shock isolation, optimal isolation

\section{Introduction}

From the modern engineering point of view impact, shock, and vibration isolators are control systems that react to the dynamic excitation (disturbance) of the object to be protected so as to mitigate undesirable effects of shock and vibration. Therefore, the theory of shock and vibration isolation can be considered as a special case of the general theory of control. Modern control theory can be considered to be composed of two areas: the theory of automatic regulation and the theory of optimal control. The theory of automatic regulation traditionally deals with the synthesis of the feedback control laws providing prescribed qualitative properties for the controlled systems. These properties are associated mostly with the stability of certain motions of the system, which the controller is attempting to maintain. The subject matter of the theory of optimal control is the construction of the control laws (either open-loop or feedback) which provide the best operating mode for the controlled system. To single out the best operating mode, a performance index (optimization criterion) is introduced that quantitatively evaluates the quality of the control process.

Pontryagin and Bellman laid the foundation for the modern theory of optimal control. Pontryagin with his colleagues have formulated and proved the maximum principle. This principle provides the necessary optimality conditions for a wide class of optimal control problems and gives an efficient mathematical tool for the practical calculation of open-loop controls. Bellman has formulated the principle of optimality and suggested the method of dynamic programming which allows the construction of a field of openloop optimal trajectories and calculation of an optimal control in feedback form. For details, see the classic books by Pontryagin, Boltyanskii, Gamkrelidze, and Mishchenko [157] and Bellman [20,21]. The fundamentals of the optimal control theory are expounded in numerous textbooks, for instance, in Bryson and Ho [48], Lee and Markus [112], and Leitmann [113].

Several treatises have been published on the theory of shock and vibration isolation viewed as control systems. In the book by Kolovskii [100] the behavior of isolation systems is investigated by the methods of nonlinear mechanics. The book provides a classification of shock and vibration absorbers, according to their intended use and mechanical structure, as well as a classification of common types of disturbances. A detailed presentation of various mathematical methods to analyze the dynamics of single- and multi-degreeof-freedom systems for different types of excitations is given. Frolov and Furman [62] investigate the dynamics of objects isolated from vibration and calculate the isolator characteristics (control laws) using the techniques of vibration theory. Mechanical properties of the isolation systems which are in most common use are analyzed. Considerable attention is paid to the analysis of isolators with hydraulic devices. In the book by Kolovskii, the isolation systems are treated from the viewpoint of the automatic regulation theory. A comprehensive presentation of modern approaches to the protection of objects from shock and vibration loads can be found in the handbook Engineering $\mathrm{Vi}$ brations [61]. 
In a sense this review article could serve as an introduction to the Gordon and Breach book (1999) by the authors: "Optimal Protection from Impact, Shock, and Vibration".

\section{Optimization of characteristics of shock and vibration isolators}

Rather topical in modern engineering are problems of protection of occupants and payloads of various transport vehicles from intensive shock and vibration loads. Such loads can occur, for example, in the motion of an automobile along an uneven road at high speed or during the landing of an aircraft.

Shock loads are particularly high in crash situations. In this case, survivability of the occupants depends on the efficiency of shock isolators with which the vehicle is equipped. The need to have isolation systems that protect occupants and equipment from extremely high shock and vibration loading, on the one hand, and advances in the development of the mathematical theory of optimization, on the other hand, have stimulated the appearance of numerous publications on the optimization of shock and vibration isolation systems.

\subsection{Systems with small number of degrees of freedom}

Much of the literature deals with a single-degreeof-freedom system. In this case, the object to be protected (the body being isolated) and the movable base, on which the object is placed, are considered as rigid bodies. The object is attached to the base by an isolator. It is assumed that the base translates along a straight line and the object being isolated can move relative to the base along the same line. The consideration of such simplified systems is advisable for two reasons. First, such system models satisfactorily describe the behavior of many real systems. Second, the relative simplicity of this system model makes it possible to carry out a complete analysis and to obtain readily interpretable results. Often the simple system can be the basis of an investigation of the behavior of more complicated systems.

Consider the system shown in Fig. 1. Let $M$ and $m$ be the masses of the base and the body being isolated, respectively. A force $\sigma(t)$ specified as a function of time is applied to the base. The isolator, introduced between the body to be protected and the base, generates the force $g(x, \dot{x}, t)$, which is applied to the body and depends on the displacement $x$ of the body relative

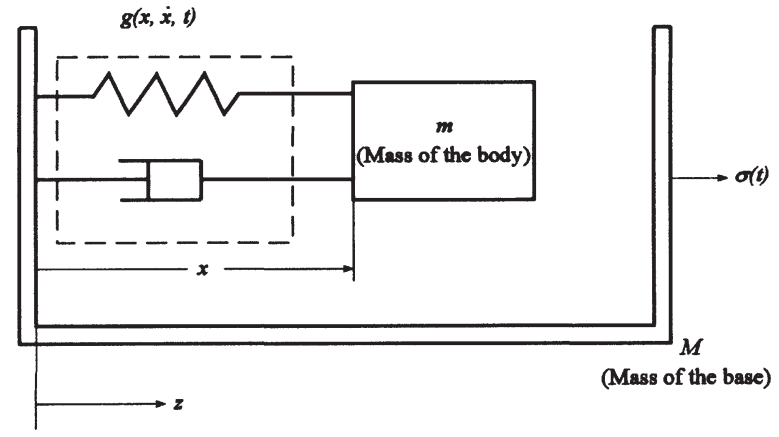

Fig. 1. The base and the body to be isolated.

to the base, its relative velocity $\dot{x}$, and time $t$. According to Newton's third law, the force $-g$ is applied by the isolator to the base. The motion of the system is governed by the set of equations

$$
\begin{aligned}
& M \ddot{z}+m(\ddot{x}+\ddot{z})=\sigma(t), \\
& m(\ddot{x}+\ddot{z})=g(x, \dot{x}, t),
\end{aligned}
$$

where $z$ is the displacement of the body with respect to a fixed (inertial) reference frame.

To obtain the equation of motion of the body being isolated, eliminate the variable $\ddot{z}$ from Eq. (1). This yields

$$
\ddot{x}-\frac{g(x, \dot{x}, t)}{\mu}=-\frac{\sigma(t)}{M}, \quad \mu=\frac{M m}{M+m} .
$$

The quantity $\mu$ is called the reduced mass of the system of two bodies. If the motion $z(t)$ of the base, rather than the force applied to it, is prescribed, the relative motion of the object being isolated is governed by the equation

$$
\ddot{x}-\frac{g(x, \dot{x}, t)}{m}=-\ddot{z}(t) .
$$

In the theory of isolation systems, the distinction is made between the kinematic and dynamic disturbances (excitations) of the system. The excitation is dynamic if the force applied to the base is prescribed and kinematic if the acceleration of the base is prescribed. Thus, Eq. (2) governs the motion of the body being isolated in the case of the dynamic excitation, and Eq. (3) corresponds to the kinematic excitation. Eqs (2) and (3) can be represented in the unified form

$$
\ddot{x}+u(x, \dot{x}, t)=F(t)
$$

where $u=-g / \mu$ and $F=\sigma / \mu$ for the case of dynamic excitation; for the case of kinematic excita- 
tion, $u=-g / m$ and $F=-\ddot{z}$. The control variable $u(x, \dot{x}, t)$, just as the force $g(x, \dot{x}, t)$, will be referred to as the characteristic of the isolator.

Introduce the two performance criteria

$$
\begin{aligned}
& J_{1}=\max _{t}|x(t)|, \\
& J_{2}=\max _{t}|u(x(t), \dot{x}(t), t)| .
\end{aligned}
$$

The performance criterion $J_{1}$ defines the peak relative displacement of the body being isolated, and the performance index $J_{2}$ defines the peak absolute acceleration of the body, which is proportional to the force transmitted to the body by the isolator.

Consider two optimization problems.

Problem 1. For the system governed by Eq. (4) subject to the initial conditions $x(0)=0, \dot{x}(0)=0$, find the control function $u$, from a specified class $Y$ of admissible controls, that minimizes the peak displacement of Eq. (5), provided the constraint

$$
|u| \leqslant U
$$

where $U$ is a prescribed constant, is satisfied.

Note that this constraint is equivalent to $J_{2} \leqslant U$.

Problem 2. For the system governed by Eq. (4) with the initial conditions $x(0)=0, \dot{x}(0)=0$, find the control function $u$, from a specified class $Y$ of admissible controls, that minimizes the peak acceleration of Eq. (6), provided the constraint on the peak displacement

$$
J_{1} \leqslant D
$$

where $D$ is a prescribed constant, is satisfied.

Problems 1 and 2 are simple but, at the same time, very important problems of the theory of shock and vibration isolation. Of particular interest is the problem of limiting isolation capabilities (limiting performance problem). In a limiting performance analysis, the isolator function $u$ is sought as a function of time alone. That is, no state-space configuration is prescribed for the isolator and the solution of Problems 1 or 2 gives the lower bound for the criterion to be minimized. The result is the absolute optimal performance, or, as mentioned, the "limiting isolation capabilities" or the "limiting performance". In control terminology, the prob- lems are approached from the standpoint of open-loop control rather than as feedback control problems. It would appear that the limiting performance problems were first defined by Sevin in the late 1950s. Limiting performance solutions are considered in numerous publications, e.g., in that by Guretskii [66] who considers the case where the criterion to be minimized is the peak displacement $J_{1}$.

It is established that the optimal isolator characteristic is piecewise constant and can always be constructed so that it assumes the values $+U,-U$, or $F(t)$. With allowance for this property, a graphical-analytical method for the construction of the optimal control was suggested by Sevin and by Guretskii [72]. In Guretskii [71], estimated values were given for the maximum number of switching points, depending on the number of the time intervals where the absolute value $|F(t)|$ of the disturbance exceeds $U$.

In Guretskii [67], estimates of the minimal and maximal displacements of the body being isolated are made. For the cases, where the disturbance has the form of a rectangular pulse, sine wave, or a cosine quarter-wave, analytical expressions are obtained that permit one to ascertain the limiting capabilities of protection.

Guretskii, Kolovskii, and Mazin [74] provide limiting isolation capabilities as well as a solution of the problem of synthesis of an isolator that consists of an elastic element and a damper. The synthesis is based on the time-history of the optimal control.

Saranchuk and Troitskii [179] solved the problem of minimization of the peak displacement of a singledegree-of-freedom system subjected to a periodic disturbance. Only the steady-state motion with a period equal to that of the excitation is considered.

Manoilenko and Rutman [122] investigated the limiting isolation capabilities for Problem 2, in which the peak acceleration is minimized. They used an "elastic analogy". The plot of the time history of the double integral with respect to time of the absolute acceleration of the object to be protected is compared to the equilibrium configuration of an elastic band. The integral approximation of the peak value of the acceleration magnitude is associated with the strain energy of the band.

Sevin and Pilkey [189] prepared a brief treatise containing limiting performance problem definitions and several solution techniques.

\subsection{Optimal feedback control of isolators}

The literature is abundant with descriptions of attempts to select optimal parameters of isolators with 
given configurations, i.e., feedback systems. The number of papers is so great that there is little incentive to discuss them here. However, some cases of special interest will be mentioned.

Troitskii [197] solved the problem of synthesis of the optimal isolator feedback characteristic for a single-degree-of-freedom system. The performance index to be minimized was the peak displacement $J_{1}$. The isolator characteristic is sought as a function of the system phase coordinates (displacement and velocity) and time. The necessary optimality conditions are established. The optimal isolator feedback characteristic is constructed for the impulse excitation $F(t)=\beta \delta(t)$. Saranchuk and Troitskii [180] investigated the problem of synthesis of the optimal isolator feedback characteristic for the case of periodic excitation.

Bolychevtsev $[39,40]$ constructed the optimal isolator feedback characteristics for the case where the external disturbance is an infinite sequence of periodically occurring instantaneous shocks. The shocks have identical intensities, either all in the same direction or in alternating directions. The optimization criterion (the performance criterion to be minimized) is the peak displacement of the body being isolated.

A problem of the optimal isolation of a multidegree-of-freedom system is considered by Guretskii [66]. Optimality is defined as the minimization of the maximum (over all coordinates) of the peak displacements in each of the coordinates.

Often in design it is required that the isolator characteristic depend only on the state variables $x$ and $\dot{x}$ and be independent of time. If the class of admissible characteristics is rather wide (for example, all piecewise continuous functions $u(x, \dot{x})$ whose absolute values do not exceed a prescribed level), then the choice of the optimal characteristic is a very complicated problem. A reasonable approach in this case is to seek the optimal characteristic among a parametric family $u\left(x, \dot{x}, a_{1}, \ldots, a_{n}\right)$, thereby reducing the original problem of optimal control to the minimization of a function of many variables. From the engineering point of view, this means that the structural schematic or configuration of the isolator has been determined and it remains to choose the isolator design variables $a_{1}, \ldots, a_{n}$ in an optimal way. Such an approach has been described by Guretskii [69] and Schmidt and Fox [182] and turned out to be rather fruitful in solving practical problems. Using this approach, Guretskii [70] determined optimal isolator characteristics for a single-degree-of-freedom system excited by a rectangular pulse. The design variables (stiffness and damp- ing coefficients) were found for the linear undamped isolator, linear damped isolator, and the isolator with a Coulomb characteristic.

Bolychevtsev, Zhiyanov and Lavrovskii [43] found the optimal design variables of the linear isolator characteristic $u\left(x, \dot{x}, a_{1}, a_{2}\right)=a_{1} x+a_{2} \dot{x}$ providing the minimum amplitude of the steady-state solution of Eq. (4). The problem is solved for an infinite sequence of periodically occurring impulsive shocks which act with the same intensity in a single direction.

The experience of solving optimal shock and vibration isolation problems shows that in many cases, commonly used isolators can provide the isolation performance close to the limiting one if the isolator design variables are chosen optimally. Bolychevtsev and Borisov [41] solved the problem similar to that considered in [39], the only difference being that the optimal isolator characteristic is sought among the twoparameter family of linear functions $a_{1} x+a_{2} \dot{x}$. It is shown that if the force allowed to be transmitted to the object being isolated is sufficiently large, the linear isolator with optimal parameters can provide the protection quality close to the limiting performance. The technical implementation of the linear isolator is much simpler than that of the optimal isolator constructed by Bolychevtsev [39].

The parametric optimization technique has been used to find near-optimal isolator characteristics by many other authors, among them are Afimiwala and Mayne [1], Bartel and Krauter [19], Karnopp and Trikha [94], Kwak, Arora and Haug [108], Wilmert and Fox [211].

\subsection{Multicriteria optimization}

The design of isolation systems with several performance criteria to be optimized, requires a multicriteria procedure. There are several approaches to the choice of the design variables of such systems. The most common approach involves the optimization with respect to one of the performance criteria, while the other criteria are constrained. The constraints are imposed so as to keep the responses corresponding to the constrained criteria within admissible limits. This approach was discussed above for the case of two performance criteria (the peak relative displacement and the peak absolute acceleration of the body being isolated).

Another approach involves the optimization with respect to a combined functional assembled from the original performance criteria, with weighting coefficients. As a rule, the combined functional is a linear 
combination of the original criteria. This approach, for example, was used by Karnopp and Trikha [196] to choose the design variables of shock and vibration isolators.

Bolychevtsev and Lavrovskii [42] suggested that a Pareto-optimal set be constructed in the space of the design variables of an isolation system to be designed. The Pareto-optimal set possesses the property that for any point of the set, there is no other point at which all performance criteria would be simultaneously improved. In other words, the Pareto-optimal set is a set of trade-off values of the design variables. Bolychevtsev and Lavrovskii apply the approach associated with the construction of the Pareto-optimal set to analyze the isolation system of the model of a walking machine with two degrees of freedom and three performance criteria. An effective method for constructing the Pareto-optimal set is described for the case of two design variables. The method involves the analysis of the level curves of the performance criteria, considered as functions of the design variables, and successive "cutting off" of nonoptimal portions of the design variable admissible domain. The approach for the calculation of isolator characteristics involving the construction of the Pareto-optimal set was also used by Rao and Hati [161], Balandin and Markov [18], Statnikov and Matusov [193].

\subsection{Efficiency of shock and vibration isolation}

Ishlinskii $[85,86]$ showed that the isolation of external disturbances applied to a base is efficient only if the acceleration (deceleration) path of the base, i.e., displacement of the base during the accelerated (decelerated) motion, does not exceed the peak relative displacement of the body being isolated. Practically, this means that the isolation provides effective protection only from impact (shock) disturbances or from highfrequency vibrations. Impact disturbances are characterized by high intensity and short duration. If the impact duration is so short that during the impact time the base moves through a distance which is much less than the rattlespace (characteristic dimension within which the body being isolated is allowed to move with respect to the base), then the isolator can be designed so that the peak displacement of the body being isolated is considerably larger than the acceleration path of the base. Vibration is characterized by long-term disturbances (the forces applied to the base for dynamic disturbances or the accelerations of the base for the kinematic disturbances) that are periodic or near-periodic, changing in magnitude and direction. If the vibration frequency is high, then the time interval during which the acceleration of the base does not change direction is small, and the distance covered by the base during this time (the acceleration path) is also small. If the acceleration path is much less than the rattlespace, then, just as in the case of impact, the peak relative displacement of the body being isolated is considerably larger than the acceleration path.

The operating quality of shock isolators is usually described in terms of certain characteristics of the transient motion of the body being isolated, whereas the quality of vibration isolators is determined by the characteristics of steady-state forced oscillations. This distinction means that shock isolation problems are treated differently from vibration isolation problems. There are numerous publications on these problems, some of which will be cited here. Problems of optimal shock isolation were investigated by Afimiwala and Mayne [1], Babitskii and Izrailovich [5], Balandin [7-10], Balandin and Malov [17], Balandin and Markov [18], Bartel and Krauter [19], Bolotnik [32, 33,35-37], Bolotnik and Kaplunov [38], Bolychevtsev $[39,40]$, Bolychevtsev and Borisov [41], Bolychevtsev, Zhiyanov, and Lavrovskii [43], Eliseev and Malinin [57], Guretskii [67,70], Guretskii, Kolovskii, and Mazin [74], Karnopp and Trikha [94], Kononenko and Podchasov [101], Ruzicka [166,167], Ryaboy [176], Schmidt and Fox [182], Sevin [186], Sevin and Pilkey [189], Troitskii [197], and Wilmert and Fox [211]. Various problems of optimal vibration isolation were considered by Akulenko and Bolotnik [2], Akulenko, Bolotnik, and Kaplunov [3], Bolotin [30,31], Furunzhiev [64], Guretskii [73], Guretskii and Mazin [75], Haug and Arora [78], Kolovskii [100], Maksimovich [120,121], Ryaboy [168,169,172-175], Saranchuk and Troitskii [179,180], Sevin and Pilkey [189], and Wang and Pilkey [207].

\section{Optimal design of isolators for a class of external disturbances}

In the publications cited above, the external disturbance function $F(t)$ in Eq. (4), was assumed to be prescribed. However, frequently in practice, information about the external disturbance is incomplete, and it is reasonable to design a shock or vibration isolation system for a class of disturbances. As indicated by Sevin and Pilkey [189], this problem has been of concern for considerable time. Saranchuk [178] treated the 
problem in a minmax (game theory) setting. With this approach the optimal isolator characteristic is sought that provides the minimum value of the optimization criterion (performance index, objective function), e.g., the peak relative displacement, for the worst disturbance $F(t)$ belonging to a specified class of functions and maximizing the optimization criterion. As a rule, the optimal isolator characteristic is sought under constraints imposed on the motion of the system. In the case of Saranchuk, the objective function was the peak relative displacement, with the absolute acceleration constrained. The problem was solved for a class of periodic disturbances and for a class of disturbances which are identically zero outside a prescribed time interval.

Bolotnik [34] applied the game theory approach to solve optimal isolation problems for the class of external disturbances $F(t)$ satisfying the integral constraint $\int_{0}^{\infty}|F(t)| \mathrm{d} t \leqslant \beta_{0}$, where $\beta_{0}$ is a specified constant. This integral constraint defines a reasonably general class of shock disturbances, including impulsive impacts $F(t)=\beta \delta(t)$, if $|\beta| \leqslant \beta_{0}$, where $\delta(t)$ is the Dirac delta function. Bolotnik [34] also investigated the optimal isolation problem for the case where the external disturbance is a series of instantaneous impacts. Unlike Bolychevtsev $[39,40]$ and Bolychevtsev, Zhiyanov and Lavrovskii [43], neither the intensities of the impacts, nor their directions are prescribed in advance. Constraints are imposed that restrict the maximum allowable intensity of each individual impact and the minimum time interval between successive impacts.

Balandin [9] investigated the problem of optimization of the design variables of an isolator consisting of a damper with a linear characteristic, a damper with the Coulomb characteristic, a nonlinear spring with a continuous characteristic, and a bang-bang spring for the class of external disturbances with the integral constraint of Bolotnik [34]. He established that for the isolator under consideration, the worst disturbance is the instantaneous impact with the maximum allowable intensity, irrespective of the values of the design variables, i.e., stiffness and damping coefficients. On the other hand, this was shown not to be the case for isolators with arbitrary characteristics. For example, for a system with an isolator consisting of a linear spring and a quadratic-law damper, an instantaneous impact is not the worst disturbance. The game approach to the optimal design of shock and vibration isolators is also discussed in the book by Sevin and Pilkey [189]. Therein, it is shown that computational techniques permit the study of optimal isolation systems with broad defini- tions of the external disturbance, for example, if the disturbance lies in a corridor prescribed as a function of time.

\section{Generalizations to motions containing rotational components}

In the majority of the works cited above, it is assumed that the base and the body to be isolated move translationally along a single direction. However, in many practical cases, the motion of the system is more complex and contains not only a translational component but also a rotational one. In this case, the number of degrees of freedom of the system increases and the form of the performance criteria becomes more complicated. If the motion of the system has a rotational component, terms describing the centripetal acceleration appear in the expression for the absolute acceleration and, moreover, the acceleration becomes dependent on the location on the body being isolated.

A problem of the optimum shock isolation of a body rotating about a fixed axis was solved by Bolotnik [35] and Bolotnik and Kaplunov [38]. The performance criterion to be minimized was the total acceleration at a given location on the body to be isolated, while a constraint was imposed on the peak absolute value of the angle of rotation of the body. The Bolotnik [35] paper deals with the optimization of the design variables of the isolator consisting of a spring with a linear characteristic and a damper with a linear or quadratic law characteristic. In the other paper, the limiting performance analysis is carried out. The results of the optimal shock isolation of a rotating body are compared with the corresponding results for a translating body.

Kulagin and Prourzin [106] and Prourzin [159] generalize the results to cases where the base and a single body being isolated perform more complex motion containing both translational and rotational components.

\section{Computational methods}

Even in solving relatively simple problems of optimal shock or vibration isolation for single-degree-offreedom systems it is often necessary to utilize numerical methods which need computer implementation. The difficulties in obtaining closed-form solutions are associated primarily with nonlinearities of the equations of motion and also with the form of performance 
indices characteristic of the optimization of shock or vibration isolators. Often, the performance criteria are represented as a maximum of a quantity representing the isolation efficiency. For example, typical criteria are the peak displacement relative to the base or the peak absolute acceleration of the body to be isolated. These difficulties become even more significant for systems with many degrees of freedom. In this case, the development of numerical methods is rather essential and topical.

Problems of optimization of shock or vibration isolator characteristics belong to a particular class of the general optimal control problem. Numerous numerical methods for solving various optimal control problems have been developed and tested. Basic numerical methods of optimal control are presented, for example, in such books as those by Chernousko and Banichuk [51], Fedorenko [60], and Moiseev [126]. Many of the methods, with modifications allowing for specific features of optimum shock and vibration isolation problems, can be applied to calculate optimal controls for isolation systems.

A complicating feature of many problems of optimal shock and vibration isolation is that the performance indices of isolation in these problems are represented as a nonadditive functional of the form

$$
J(\mathbf{u})=\max _{t \in\left[t_{0}, T\right]} \Phi(\mathbf{x}(t), \mathbf{u}(\mathbf{x}(t), t), t),
$$

where $\mathbf{x}$ is the phase vector of the system, $\mathbf{u}$ is the control vector function, $\Phi(\mathbf{x}, \mathbf{u}, t)$ is a prescribed function, and $t_{0}$ and $T$ are the initial and the terminal instants of the motion, respectively. Sometimes, functionals of the form of Eq. (7) are referred to as maximum-type functionals. The functionals $J_{1}$ and $J_{2}$ of Eqs (5) and (6) are particular cases of the functional $J(\mathbf{u})$ of Eq. (7). Optimal control problems with functionals of such a type cannot be tackled with the traditional optimal control techniques. Hence, specific approaches to these problems were developed.

There are a number of methods for the numerical solution of optimal control problems with maximumtype functionals. One of the simplest approaches involves partitioning the time interval $\left[t_{0}, T\right]$ into subintervals and setting the control function to be constant or linearly varying on each of the subintervals. In such a way, the original optimal control problem can be reduced to the minmax problem for a function of a finite number of variables, the maximum being taken over all discretization points and the minimum over the values of the control variables on the subintervals. The cal- culation of a trial value of the function, for which the minmax is to be found, may require numerically integrating the equations of motion for a specified set of the control variable values on the discretization subintervals. The theory of the minmax of functions of a finite number of variables and the numerical algorithms based on this theory are presented in the book by Demyanov and Malozemov [55]. One of the approaches in question was applied to the limiting performance analysis of shock and vibration isolation systems by Vinogradova [204]. The attractive feature of the methods based on the discretization of the control function is their simplicity. However, these methods are complicated because in many practical cases, the discrete mesh must be very fine to provide a high precision for the solution, which can lead to computational challenges.

Another approach involves an appropriate approximation of the maximum-type functional by an additive functional (for example, integral or terminal functional) which can be minimized by the traditional optimal control methods. For the typical case, where $\Phi(\mathbf{x}, \mathbf{u}, t)>0$, the maximum-type functional $J(\mathbf{u})$ of Eq. (7) is often replaced by the integral

$$
J_{\nu}(\mathbf{u})=\int_{t_{0}}^{T} \Phi^{\nu}(\mathbf{x}(t), \mathbf{u}(\mathbf{x}(t), t), t) \mathrm{d} t
$$

where $\nu$ is a sufficiently large positive number. This replacement is based on the well-known relation

$$
\begin{aligned}
& \lim _{\nu \rightarrow \infty}\left[J_{\nu}(\mathbf{u})\right]^{1 / \nu} \\
& \quad=J(\mathbf{u})=\max _{t \in\left[t_{0}, T\right]} \Phi(\mathbf{x}(t), \mathbf{u}(\mathbf{x}(t), t), t),
\end{aligned}
$$

which is valid under rather general conditions.

Sometimes, if the function $\Phi$ is independent of $\mathbf{u}$, the maximum-type functional is replaced by a terminal functional with an unknown time for the termination of the process. This approach was used, for example, by Kuznetsov and Chernousko [107] and Troitskii [197] to solve some problems of optimal control in mechanical systems whose performances were evaluated by maximum-type functionals. The condition of the vanishing of the total derivative of the function $\Phi(\mathbf{x}(t), t)$ with respect to time is adopted as the condition of the process termination. At this instant, the necessary condition for the extremum of the function $\Phi(\mathbf{x}(t), t)$ is satisfied. This approach can be effective only for the rare cases where the first local extremum of the function $\Phi(\mathbf{x}(t), t)$ is the global maximum of this function on the 
interval $\left[t_{0}, T\right]$ for any control $\mathbf{u}$. In the other cases, the use of this method is problematic.

Because of the practical importance of optimal control problems with maximum-type functionals (in particular, in connection with optimal shock and vibration isolation), computational methods have been developed that take into account the special mathematical features of these problems. Viktorov and Larin [201] suggested a computational algorithm which is a modification of the method of gradient descent in the space of control functions [192] for maximum-type functionals. This method was applied to solve the optimal isolation problem posed by Guretskii [66] for a singledegree-of-freedom system for two special kinds of external disturbances.

A number of methods for numerical solution of optimal control problems with the functional of the form $\max _{t} \Phi(\mathbf{x}(t), t)$ were developed by Silina [191] and Timoshina and Shablinskaya [195]. These methods are based on the necessary optimality conditions. It is assumed that the function $\Phi(\mathbf{x}(t), t)$ has a finite number of points of local extrema for any admissible control. This property permits the reduction of the original problem of optimal control to the search for the extremum in a finite-dimensional space, which is simpler computationally. The methods developed were applied to the limiting performance analysis of shock isolation systems.

Sevin and Pilkey $[187,189]$ used the dynamic programming technique to solve control problems with maximum-type functionals for single-degree-of-freedom systems. In [187], the worst disturbance problem is solved for a body attached to a base by a linear isolator. The class of admissible disturbances is defined as the class of functions of time with a prescribed integral. In [189], dynamic programming is applied to solve the problem of limiting isolation capabilities for a system subject to completely or incompletely prescribed disturbances. In both cases, the peak relative displacement of the body being isolated was chosen to be the performance index.

Wang and Pilkey [207] suggested a method for approximate solution of the limiting performance problem for linear multi-body systems subjected to periodic disturbances. For steady-state motions the control is sought in the form of a truncated Fourier series in terms of harmonics whose frequencies are multiples of those of the external disturbance. The Fourier coefficients are determined by numerically solving a nonlinear programming problem so as to provide the minimum for the performance criterion. Even more signifi- cant is the use of the Fourier series approach for problems of optimal isolation of linear systems subject to transient excitations.. This leads to a linear programming problem in which the coefficients of the Fourier series are the unknowns. In recent years this has become a very viable method since the number of unknowns is less than for the approach discussed earlier in which the isolator force is discretized as a piecewise constant function.

In Larin [110], a numerical algorithm for optimization of the design variables of single-degree-offreedom isolation systems is presented. The performance criterion to be minimized is the peak displacement of the body being isolated. The method is based on the reduction of the original problem to a nonlinear programming problem which is solved by the gradient descent in the design variable space. On each iteration, to calculate the objective function it is necessary to integrate the equation of motion and to calculate the peak displacement of the body.

Hsiao, Haug and Arora [82] developed a numerical method for the optimization of dynamical systems with many degrees of freedom for the case where the criterion to be minimized has the form of a maximum of a function of the system phase variables. The approach involves an equivalent replacement of the maximumtype functional by an integral functional and application of the Lagrange multiplier technique. The method was used to calculate the optimal design variables of spring-and-damper isolators for systems with one and two degrees of freedom.

Sevin and Pilkey [189] suggested a numerical method for determining the optimal design variables of shock and vibration isolation systems which does not require integrating the equations of motion on each iteration but needs the limiting performance problem to be solved beforehand. The heuristic basis of the method is the contention that the characteristics of a well-designed system must be close to those providing the limiting performance. Hence, in this approach, the feedback control parameters are chosen such that the time history of the feedback control force is as close as possible to the open loop optimal control corresponding to the limiting performance. The practical application of this method seems to be limited. However, it can be used for preliminary testing calculations, for example, with the aim of finding out whether a selected design of the isolation system allows adjusting the design variables so as to provide the limiting performance characteristics for the shock or vibration isolation system. 


\section{Monographs on the optimal shock and vibration isolation}

There are several monographs devoted to optimal shock and vibration isolation. A fundamental book in this field was written by Sevin and Pilkey [189]. This book presents general mathematical statements of basic problems of optimal shock and vibration isolation, describes typical performance criteria and constraints imposed on the performance characteristics, control variables, and design variables of isolation systems, and discusses the adequacy of the mathematical description relative to the properties of real isolation systems used in engineering. A classification of external disturbances and types of isolators is given. The problem of the optimal isolation of shock and vibration is stated in a general form for a system with an arbitrary number of degrees of freedom. The limiting performance problem and the problem of parametric optimization are presented as practically important, distinct, special cases of the general optimization problem. A linear programming solution is outlined for the limiting performance problem of multidegree-of-freedom linear systems. Particular attention is paid to single-degree-of-freedom systems. For such systems, it is proved that the optimal open-loop control providing the limiting performance for the isolation system can be constructed in the form of a piecewise constant function of time that takes either upper or lower boundary values. A graphical-analytical method to construct the optimal isolator characteristic (optimal control) for the limiting performance problem is suggested. In major features, this method is similar to the method of Guretskii [72]. Various numerical methods for constructing the optimal isolator characteristics or determining the optimal design variables for isolation systems are discussed. In particular, linear programming (for linear systems) and dynamic programming (for linear and nonlinear systems) solutions for the limiting performance problem are developed. The book is richly illustrated with numerical examples, graphs, and figures. An annotated bibliography of works dealing with optimum shock and vibration isolation is presented at the end of the monograph.

The monograph by Furunzhiev [63] is devoted mostly to stochastic problems of optimal vibration isolation of systems subjected to random disturbances. The author discusses mathematical models of systems with stochastically characterized performance criteria. Various problems of optimal control and parametric optimization of vibration isolators are stated and meth- ods for their solution are given. The book also contains descriptions of computational techniques for the statistical analysis of vibration isolation systems with the aid of a computer. Numerical examples for the calculation of vibration isolation systems for transport vehicles are presented.

The book by Kolovskii [100] contains various statements of optimal shock and vibration isolation problems and discusses different approaches to their solution. In particular, the problem of the limiting isolation capabilities (limiting performance problem) is formulated. The graphical-analytical method of Guretskii [72] and various numerical methods to solve the limiting performance problem for single-degree-offreedom isolation systems are presented. A comparative analysis of these methods is given. Various approaches to the synthesis of optimal or near-optimal feedback isolator characteristics are expounded. Particular attention is paid to the optimal isolation of rigid bodies performing complex motion from shock or vibration. Mathematical models of isolation systems for rigid bodies are considered, statements of the corresponding optimization problems are presented, and methods for solving these problems are discussed. The majority of the issues discussed in the monograph by Kolovskii are illustrated with numerical examples. A bibliography of works on the optimization of shock and vibration isolation systems is presented.

In the book by Bolotnik [36], a complete solution of the problem of the optimal isolation of a singledegree-of-freedom system from an impulsive impact is given. The performance criteria are the peak displacement of the body being isolated with respect to the base and the peak acceleration of this body with respect to a fixed reference frame. Cases where the body moves along a straight line and where it rotates about an axis are considered. The optimal performance characteristics are obtained, and feedback isolators providing the limiting performance or approximations to it are discussed. For the case of the rectilinearly moving body, all spring-and-damper isolators with power-law characteristics that provide the limiting performance for the shock isolation system are identified. The problem of optimization of the isolator characteristic for a class of external disturbances is considered in the game theory (minmax) setting. The optimal and near-optimal feedback controls are constructed for the case where the body being isolated moves rectilinearly and the integral of the absolute value of the applied force to which the system can be subjected is constrained by a prescribed quantity. A number of problems for the opti- 
mal vibration isolation of a mechanism containing an unbalanced rotor are solved.

Genkin and Ryaboy [65] investigate multi-mass absorbers (isolators) for harmonic vibrations. The isolators consist of inertial and elastic members. The problem of minimization of the isolator mass, provided the dynamic load transmitted to the object to be protected is reduced to a prescribed level, is solved. The reduction of the dynamic load is characterized by the transmissibility coefficient of the system. In the general case, the prescribed reduction level may depend on the vibration frequency. Estimates for the minimal mass of the isolator, depending on the maximum allowable value of the transmissibility coefficient, are given. The authors suggest a number of design schematics for optimal vibration isolators.

\section{References}

[1] K.A. Afimiwala and R.W. Mayne, Optimum design of an impact absorber, J. of Engineering for Industry 96 (1974), 124 130.

[2] L.D. Akulenko and N.N. Bolotnik, On the vibration isolation of rotating parts of mechanisms, Izv. AN SSSR. Mekhanika Tverdogo Tela (Mechanics of Solids), No. 4, (1979), pp. 4047 (in Russian).

[3] L.D. Akulenko, N.N. Bolotnik and A.A. Kaplunov, Investigation and optimization of an isolation system of rotating parts of mechanisms with dry friction, Izv. AN SSSR. Mekhanika Tverdogo Tela (Mechanics of Solids), No. 1, (1982), pp. 5665 (in Russian).

[4] F.R. Arnold, Steady-state behavior of systems provided with non-linear dynamic vibration absorbers, J. Applied Mechanics 22 (1955), 487-492.

[5] V.I. Babitskii and U.Ya. Izrailovich, On a problem of optimal isolation, Izv. AN SSSR. Mekhanika Tverdogo Tela (Mechanics of Solids), No. 5 (1968), 44-46.

[6] J. T. Bailey and W.D. Pilkey, A worst balance analysis of flexible rotating shafts, J. Sound and Vibration 35 (1974), 301308.

[7] D.V. Balandin, Parametric optimization of nonlinear isolators, Izv. AN SSSR. Mekhanika Tverdogo Tela (Mechanics of Solids), No. 3 (1985), 72-74 (in Russian).

[8] D.V. Balandin, Optimization of shock isolators for incompletely prescribed mass of the object to be protected, Izv. AN SSSR. Mekhanika Tverdogo Tela (Mechanics of Solids), No. 3 (1988), 27-31 (in Russian).

[9] D.V. Balandin, Optimization of shock isolators for a class of external disturbances, Izv. AN SSSR. Mekhanika Tverdogo Tela (Mechanics of Solids), No. 1 (1989), 53-60 (in Russian).

[10] D.V. Balandin, Optimal control of damping in shock isolators, Izv. AN SSSR. Mekhanika Tverdogo Tela (Mechanics of Solids), No. 6 (1989), 66-73 (in Russian).
[11] D.V. Balandin, On maximum energy of mechanical systems under shock disturbances, Shock and Vibration 1 (1993), 135144.

[12] D.V. Balandin, On the perturbation accumulation in linear and nonlinear systems under shock disturbances, Prikladnaya Matematika i Mekhanika (Applied Mathematics and Mechanics) 57(1) (1993), 20-25 (in Russian).

[13] D.V. Balandin, Limiting capabilities of control of a linear system, Doklady RAN 334(5) (1994), 571-573 (in Russian).

[14] D.V. Balandin, Limiting capabilities of vibration isolation of a multi-mass elastic structure, Izv. RAN. Mekhanika Tverdogo Tela (Mechanics of Solids), No. 6 (1994), 10-17 (in Russian).

[15] D.V. Balandin, Optimal damping of vibrations in elastic objects, Prikladnaya Matematika i Mekhanika (Applied Mathematics and Mechanics) 59(3) (1995), 464-474 (in Russian).

[16] D.V. Balandin, Limiting vibroisolation control of an oscillating string on a moving base, Shock and Vibration 2 (1995), 163-171.

[17] D.V. Balandin and Yu.Ya. Malov, Optimization of parameters of isolators for random shock disturbances, Izv. AN SSSR. Mekhanika Tverdogo Tela (Mechanics of Solids), No. 3 (1987), 27-33 (in Russian).

[18] D.V. Balandin and A.A. Markov, Optimization of parameters of nonlinear shock isolators, Izv. AN SSSR. Mekhanika Tverdogo Tela (Mechanics of Solids), No. 2 (1986), 61-66 (in Russian).

[19] D.L. Bartel and A.I. Krauter, Time domain optimization of a vibration absorber, J. Engineering for Industry, Transactions ASME, Ser. B 93(3) (1971), 799-804.

[20] R. Bellman, On the minimum of maximum deviation, Quarterly of Applied Mathematics 14 (1957), 419-422.

[21] R. Bellman, Dynamic Programming, Princeton Univ. Press, Princeton, NJ, 1957.

[22] R. Bellman, On minimizing the probability of a maximum deviation, IRE Transactions Automatic Controls 7 (1962), 45.

[23] R. Bellman and S. Dreyfus, Applied Dynamic Programming, Princeton Press, Princeton, NJ, 1962.

[24] E.K. Bender, Optimization of the random vibration characteristics of vehicle suspensions. Ph.D. Dissertation, MIT, 1967.

[25] E.K. Bender, Optimum linear preview control with application to vehicle suspension, J. Basic Engineering 90 (1968), 213-221.

[26] E.K. Bender, Some fundamental limitations of active and passive vehicle-suspension systems, SAE 680750, 1968.

[27] E.K. Bender and I.L. Paul, Analysis of optimum and preview control of active vehicle suspension, DOT, PB176137, 1967.

[28] R.E. Blake, Near-optimum shock mounts for protecting equipment from an acceleration pulse, Shock and Vibration Bulletin 35 (1966), 133-146.

[29] D.B. Bogy and P.R. Paslay, Evaluation of fixed point method of vibration analysis for particular system with initial damping, J. Engineering for Industry 85 (1963), 233-236.

[30] V.V. Bolotin, Theory of reliability for mechanical systems with finite number of degrees of freedom, Izv. AN SSSR Mekhanika Tverdogo Tela (Mechanics of Solids), No. 5 (1969), 73-81 (in Russian). 
[31] V.V. Bolotin, Theory of optimal protection from vibration under stochastic disturbances, Trudy Moskovskogo Energeticheskogo Instituta, 74 (1970), 5-15.

[32] N.N. Bolotnik, Optimization of parameters of some mechanical vibratory systems, Izv. AN SSSR. Mekhanika Tverdogo Tela (Mechanics of Solids), No. 5 (1974), 33-40 (in Russian).

[33] N.N. Bolotnik, Optimization of parameters of a mechanical vibratory system with dry friction, Izv. AN SSSR. Mekhanika Tverdogo Tela (Mechanics of Solids), No. 5 (1975), 56-58 (in Russian).

[34] N.N. Bolotnik, Optimal isolation problems for classes of external disturbances, Izv. AN SSSR. Mekhanika Tverdogo Tela (Mechanics of Solids), No. 4 (1974), 34-41 (in Russian).

[35] N.N. Bolotnik, Optimal isolation of torsional vibrations, $I z v$. AN SSSR. Mekhanika Tverdogo Tela (Mechanics of Solids), No. 5 (1977), 51-55 (in Russian).

[36] N.N. Bolotnik, Optimization of Shock and Vibration Isolation Systems, Nauka, Moscow, 1983 (in Russian).

[37] N.N. Bolotnik, Optimization of characteristics and design variables of shock isolation systems and vibration technological machines, Izv. RAN. Tekhnicheskaya Kibernetika, No. 1 (1993), 62-67 (in Russian).

[38] N.N. Bolotnik and A.A. Kaplunov, Some problems of optimal control of rotation of a rigid body, Izv. AN SSSR. Mekhanika Tverdogo Tela (Mechanics of Solids), No. 5 (1980), 14-24 (in Russian).

[39] E.M. Bolychevtsev, The choice of optimal isolation law under shock disturbances, Izv. AN SSSR. Mekhanika Tverdogo Tela (Mechanics of Solids), No. 5 (1971), 51-54 (in Russian).

[40] E.M. Bolychevtsev, Synthesis of optimal controls minimizing the maximum displacement under the action of disturbances, Scientific Transactions of the Institute of Mechanics of Moscow State University, No. 22 (1973), 47-55 (in Russian).

[41] E.M. Bolychevtsev and A.P. Borisov, Shock isolation in a linear system, Izv. AN SSSR. Mekhanika Tverdogo Tela (Mechanics of Solids), No. 2 (1976), 55-57 (in Russian).

[42] E.M. Bolychevtsev and E.K. Lavrovskii, On constructing a pareto-optimal set for certain optimization problems, $I z v$. $A N$ SSSR. Mekhanika Tverdogo Tela (Mechanics of Solids) 12 (1977), 33-40 (in Russian).

[43] E.M. Bolychevtsev, N.I. Zhiyanov, and E.K. Lavrovskii, Optimization of parameters of an oscillatory system subject to impulse disturbances, Vestnik MGU (Bulletin of Moscow State University), Ser. 1, No. 6 (1975), 103-106 (in Russian).

[44] J. A. Bonesho and J. S. Bollinger, How to design a selfoptimizing vibration damper, Machine Design 40 (1968), 123-127.

[45] J. E. Brock, A note on the damped vibration absorber, J. Applied Mechanics 13 (1946), A284.

[46] J. E. Brock, Theory of the damped dynamic vibration absorber for inertial disturbances, J. Applied Mechanics 16 (1949), p. A86.

[47] S.H. Brooks, A comparison of maximum-seeking methods, Operations Research 7 (1959), 430-457.

[48] A.E. Bryson and Y.C. Ho, Applied Optimal Control, John Wiley and Sons, New York, 1975.
[49] W.J. Carter and F.C. Liu, Steady-state behavior of non-linear dynamic vibration, J. Applied Mechanics 28 (1961), 67-70.

[50] Y.H. Chen, A.J. Kalinowski and W.D. Pilkey, Indirect synthesis of multidegree-of-freedom transient systems, J. Optimization Theory and Applications 20 (1976), 1133-1146.

[51] F.L. Chernousko and N.V. Banichuk, Variational problems of mechanics and control. Numerical methods, Nauka, Moscow, 1974 (in Russian).

[52] F.L. Chernousko and A.A. Melikyan, Game Problems of Control and Search, Nauka, Moscow, 1978 (in Russian).

[53] K.T. Cornelius, A study of the performance of an optimum shock mount," damped, resilient mount, Shock and Vibration Bulletin 38 (1968), 213-219.

[54] J. R. Crandall, W.D. Pilkey, W. Kang and C.R. Bass, Sensitivity of occupant response subject to prescribed corridors, $J$. Shock and Vibration 3 (1996), 435-450.

[55] V.F. Demyanov and V.N. Malozemov, Introduction to Minmax, Nauka, Moscow, 1972 (in Russian).

[56] T.F Derby and P.C. Calcaterra, Response and optimization of an isolation system with relaxation type damping, Shock and Vibration Bulletin 40(5) (1970), 203-216.

[57] V.V. Eliseev and L.M. Malinin, On the shock isolation of the shaft-line support, Problemy Mashinostroeniya i Nadezhnosti Mashin, No. 2 (1990), 29-35 (in Russian).

[58] R.A. Eubanks, Investigation of a rational approach to shock isolator design, Shock and Vibration Bulletin 34, No. 3 (1964), $157-168$.

[59] K.C. Falcon, Optimization of vibration absorbers: a graphical method for use on idealized systems with restricted damping, J. Mechanical Engineering Science 9 (1967), 374-381.

[60] R.P. Fedorenko, Approximate Solution of Optimal Control Problems, Nauka, Moscow, 1978 (in Russian).

[61] K.V. Frolov, ed., Vibration in Engineering. Protection from Vibration and Shock, Vol. 6, Mashinostroenie, Moscow, 1995.

[62] K.V. Frolov and F.A. Furman, Applied Theory of Vibration Isolation Systems, Hemisphere Pub. Corp., New York, 1990.

[63] R.I. Furunzhiev, Design of Optimal Vibration Protection Systems, Vysshaya Shkola, Minsk, 1971 (in Russian).

[64] R.I. Furunzhiev, Automatic Design of Oscillatory Systems, Vysshaya Shkola, Minsk, 1977 (in Russian).

[65] M.D. Genkin and V.M. Ryaboy, Elastic-Inertial Vibration Isolation Systems: Limiting Performance, Optimal Configurations, Nauka, Moscow, 1988 (in Russian).

[66] Guretskii, On one problem of optimal control, Izv. AN SSSR. Mekhanika, No. 1 (1965), 159-162 (in Russian).

[67] V.V. Guretskii, Limiting capabilities of the equipment protection against shock action, Izv. AN SSSR. Mekhanika, No. 2 (1965), 76-81 (in Russian).

[68] V.V. Guretskii, On the maximum of the displacement of an optimally isolated object, Trudy LPI (Leningradskii Politekhnicheskii Institut), Dinamika i Prochnost Mashin, No. 252 (1965), 16-23 (in Russian).

[69] V.V. Guretskii, Determination of optimal parameters for shock isolators, Trudy LPI (Leningradskii Politekhnicheskii Institut), Mekhanika i Protsessy Upravleniya, No. 266 (1966), 17-23 (in Russian). 
[70] V.V. Guretskii, On the choice of optimal parameters for characteristics of shock isolators, Izv. AN SSSR. Mekhanika Tverdogo Tela. Inzhenernyi Zhurnal (Mechanics of Solids), No. 1 (1966), 167-170 (in Russian).

[71] V.V. Guretskii, On the number of the switching points of the optimal control in the problem of minimization of the peak displacement, Izv. AN SSSR. Mekhanika Tverdogo Tela. Inzhenernyi Zhurnal (Mechanics of Solids), No. 1 (1968), 26-30 (in Russian).

[72] V.V. Guretskii, On the problem of minimizing the maximum displacement, Trudy LPI (Leningradskii Politekhnicheskii Institut), Mekhanika i Protsessy Upravleniya. Vychislitel'naya Matematika, No. 307 (1969), 11-21 (in Russian).

[73] V.V. Guretskii, On the limiting isolation capabilities for vibration loads, Izv. AN SSSR. Mekhanika Tverdogo Tela (Mechanics of Solids), No. 1 (1969), 51-54 (in Russian).

[74] V.V. Guretskii, M.Z. Kolovskii and L.S. Mazin, On the limiting capabilities of shock isolation, Izv. AN SSSR. Mekhanika Tverdogo Tela (Mechanics of Solids), No. 6 (1970), 17-22 (in Russian).

[75] V.V. Guretskii and L.S. Mazin, On the limiting capabilities of active vibration isolation, Prikladnaya Mekhanika 12, No. 7 (1976), 109-113.

[76] E. Hahnkamm, Die Dampfung von Fundamentschwingungen bei Veränderlicher Erreger Frequenz, Ingenieur-Archiv. 4 (1933).

[77] C.M. Harris and C.E. Crede, Shock and Vibration Handbook, McGraw-Hill, New York, 1996.

[78] E.J. Haug and J. S. Arora, Applied Optimal Design. Mechanical and Structural Systems, Wiley-Interscience Publ., New York, 1979.

[79] A.R. Henney, Damping of continuous systems, Engineer 215 (1963), 572-574.

[80] A.R. Henney and J. P. Raney, The optimization of damping of four configurations of a vibrating beam, J. Engineering for Industry 85 (1963), 259-264.

[81] D. Hrovat and H. Hubbard, A comparison between jerk optimal and acceleration optimal vibration, J. Sound and Vibration 112 (1987), 201-208.

[82] M.H. Hsiao, E.J. Haug and J. S. Arora, A state space method for optimal design of vibration isolators, J. Mechanical Design 101 (1979), 309-314.

[83] M.S. Hundal, Impact absorber with linear spring and quadratic law damper, J. Sound and Vibration 48 (1976), 189 193.

[84] M.S. Hundal, Response of a base excited system with coulomb and viscous friction, J. Sound and Vibration 64 (1979), 371-378

[85] A.Y. Ishlinsky, Mechanics of gyroscopic systems, Izdatel'stvo AN SSSR, Moscow, 1963 (in Russian)

[86] A.Y. Ishlinsky, Classical Mechanics and Inertia Forces, Nauka, Moscow, 1987 (in Russian).

[87] C.D. Johnson, Optimal control with Chebyshev minimax performance index", J. Basic Engineering 89 (1967), 251-262.

[88] S. Karlin, Mathematical Methods and Theory in Games, Programming, and Economics, Pergamon Press, London, 1959.
[89] A.J. Kalinowski, Optimum performance characteristics and synthesis of shock isolation systems, Ph.D. dissertation, Illinois Institute of Technology, 1969.

[90] A.J. Kalinowski and W.D. Pilkey, Identification of shock and vibration forces, in: System Identification of Vibrating Structures and Mathematical Models from Test Data, ASME (1972), 73-86.

[91] A.J. Kalinowski and W.D. Pilkey, Design for incompletely prescribed loading," J. Engineering Mechanics Division, ASCE 101 (1975), 505-510.

[92] D.C. Karnopp, Applications of random process theory to the design and testing of ground vehicles, Transportation Research 2 (1968), 269-278.

[93] D.C. Karnopp, Continuum model study of preview effects in actively suspended long trains, J. Franklin Institute $\mathbf{2 8 5}$ (1968), 251-260.

[94] D.C. Karnopp and A.K. Trikha, Comparative study of optimization techniques for shock and vibration isolation, J. Engineering for Industry 91 (1969), 1128-1132.

[95] E.M. Kerwin, Jr., Damping of flexural waves by a constrained viscoelastic layer, J. Acoustical Society of America 31 (1959), 952-962.

[96] L. Kitis, W.D. Pilkey and B.P. Wang, Optimal frequency response modification by added passive structures, J. Aircraft 20 (1983), 897-898.

[97] L. Kitis, W.D. Pilkey and B.P. Wang, Optimal frequency response shaping by appendant structures, J. Sound and Vibration 95 (1984), 161-175.

[98] L. Kitis, B.P. Wang and W.D. Pilkey, Vibration reduction over a frequency range, J. Sound and Vibration 89 (1983), 559569.

[99] M.Z. Kolovskii, Nonlinear Theory of Vibration Protection Systems, Nauka, Moscow, 1966 (in Russian).

[100] M.Z. Kolovskii, Automatic Control of Vibration Protection Systems, Nauka, Moscow, 1976 (in Russian).

[101] V.O. Kononenko and N.P. Podchasov, On the optimum active damping of oscillations, Izv. AN SSSR. Mekhanika Tverdogo Tela (Mechanics of Solids), No. 3 (1973), 3-10 (in Russian).

[102] N.N. Krasovskii, Game Problems of Motion Encounter, Nauka, Moscow, 1970 (in Russian).

[103] N.N. Krasovskii, Control of a Dynamic System. The Problem of Minimum of the Guaranteed Result, Nauka, Moscow, 1985 (in Russian).

[104] H.W. Kriebel, A study of the practicality of active shock isolation. Ph.D. dissertation, Stanford University, 1966.

[105] H.W. Kriebel, A study of the feasibility of active shock isolation, Ingenieur-Archiv. 36 (1968), 371-380.

[106] V.V. Kulagin and V.A. Prourzin, Optimal control of the spatial motion of a rigid body to be isolated from shock, $I z v$. AN SSSR. Mekhanika Tverdogo Tela (Mechanics of Solids), No. 3 (1985), 8-15.

[107] A.G. Kuznetsov and F.L. Chernousko, On the optimal control minimizing the extremum of a function of the phase variables, Kibernetika, No. 3 (1968), 50-55 (in Russian).

[108] B.M. Kwak, J.S. Arora and E.J. Haug, Optimum design of damped vibration absorbers over a finite frequency range, AIAA Journal 13 (1975), 540-542. 
[109] T.N.T. Lack and M. Enns, Optimal control trajectories with minimax objective functions by linear programming, IEEE Trans. Automatic Controls (1967), 749-752.

[110] R.M. Larin, Gradient method for solving an approximate problem of optimal isolator synthesis, Trudy LPI (Leningradskii Politekhnicheskii Institut), Mekhanika i Protsessy Upravleniya. Vychislitel'naya Matematika, (1969), 155-162 (in Russian).

[111] V.B. Larin, Statistical Problems of Vibration Protection, Naukova Dumka, Kiev, 1974 (in Russian).

[112] F.B. Lee and L. Markus, Foundations of Optimal Control Theory, John Wiley and Sons, New York, 1967.

[113] G. Leitmann, The Calculus of Variations and Optimal Control, Plenum Press, New York, 1981.

[114] E.S. Levitan, Forced oscillation of spring-mass system having coulomb and viscous damping, J. Acoustic Society of America 32 (1960), 1226-1269.

[115] F.M. Lewis, Extended theory of viscous vibration damper, J. Applied Mechanics 22 (1955), 377-382.

[116] T. Liber and E. Sevin, Optimal shock isolation synthesis, Shock and Vibration Bulletin 35(5) (1966), 203-215.

[117] T.W. Lim, Limiting performance based structural and control optimization for large vibrating structures. Ph.D. dissertation, University of Virginia, 1989.

[118] T.W. Lim and W.D. Pilkey, Indirect synthesis of structural parameters for transient response optimization, in: Proc. 30th AIAA/ASME/SAE Structural Dynamics and Materials Conference (1989), 1-6.

[119] R.M. Little, The application of linear programming techniques to balancing flexible rotors. Ph.D. dissertation, University of Virginia, 1971.

[120] Yu.P. Maksimovich, On the optimal vibration isolation, Mashinovedenie, No. 4 (1970), 13-20 (in Russian).

[121] Yu.P. Maksimovich, On the attainable quality of protection from periodic vibration, Izv. AN SSSR. Mekhanika Tverdogo Tela (Mechanics of Solids), No. 5 (1970), 23-27 (in Russian).

[122] V.D. Manoilenko and Yu.L. Rutman, An elastic analogy for the optimal control of an isolated object when the peak load is minimized, Izv. AN SSSR. Mekhanika Tverdogo Tela (Mechanics of Solids), No. 6 (1974), 3-11 (in Russian).

[123] L.S. Mazin, The influence of errors in determining the inertial characteristics of a rigid body on the system of its isolation, Izv. AN SSSR. Mekhanika Tverdogo Tela (Mechanics of Solids), No. 1 (1969), 44-51 (in Russian).

[124] J.C. McMunn, Multi-parameter optimum damping in linear dynamical systems. Ph.D. dissertation, University of Minnesota, 1967.

[125] J.C. McMunn and R. Plunkett, Multi-parameter optimum damping in linear dynamical systems, ASME Paper 69VIBR-42, 1969.

[126] N.N. Moiseev, Elements of Theory of Optimal Systems, Nauka, Moscow, 1975 (in Russian).

[127] Yu.I. Neimark, Calculating an optimal vibration isolator, $I z v$. AN SSSR. Mekhanika Tverdago Tela (Mechanics of Solids), No. 5 (1966), 182 (in Russian).

[128] V.H. Neubert, Dynamic absorbers applied to bar that has solid damping, J. Acoustical Society of America 36 (1964), 673680.
[129] B.E. O'Conner, The viscous torsional vibration damper, SAE Trans. 1 (1947), 87-97.

[130] J. Ormondroyd and J.P. Den Hartog, Theory of the dynamic vibration absorber, Trans. ASME 50 APM-50-7 (1928), 9-22.

[131] Pilkey, Optimization of shock isolation systems, Trans. SAE (1968), 2900-2909.

[132] W.D. Pilkey, Interactive optimal design of isolation systems, Shock and Vibration Bulletin 41(2) (1970), 47-51.

[133] W.D. Pilkey, Optimal shock absorbers in freight cars, ASME Rail Transportation Transactions, (1973) 73-RT-3.

[134] W.D. Pilkey, The chebyshev norm as a deterministic alternative for problems with uncertainties, J. Probablistic Engineering Mechanics 11 (1996), 215-219.

[135] W.D. Pilkey, J. Bailey and J.D. Smith, A computational technique for optimizing correction weights and axial location of balance planes of rotating shafts, J. Vibrations, Acoustics, Stress, and Reliability in Design 105 (1983), 90-93.

[136] W.D. Pilkey, Y.H. Chen and A.J. Kalinowski, The use of general purpose computer programs to derive equations of motion for optimal isolation studies, Shock and Vibration Bulletin 46(4) (1976), 269-276.

[137] W.D. Pilkey and A.J. Kalinowski, Identification of shock and vibration forces, Identification of Vibrating Structures, ASME, (1972), 73-86.

[138] W.D. Pilkey and A.J. Kalinowski, Response bounds for structures with incompletely prescribed loading, Shock and Vibration Bulletin 43(2) (1973), 31-42.

[139] W.D. Pilkey and A.J. Kalinowski, Design for incompletely prescribed loading, Engineering Mechanics Journal 101 (1975), 505-510.

[140] W.D. Pilkey, W. Kang and L. Kitis, Best and worst disturbance analysis of structures under crash pulse loadings, Crashworthiness and Occupant Protection in Transportation Systems, ASME, AMD 156/BED-Vol. 25 (1993), 105-113.

[141] W.D. Pilkey, W. Kang and U. Schramm, Limiting performance analysis of large systems using an approximate optimization scheme, Finite Elements in Analysis and Design 27 (1997), 7-17.

[142] W.D. Pilkey and L. Kitis, Limiting performance of shock isolation systems by a modal approach, Earthquake Engineering and Structural Dynamics 14 (1986), 75-81.

[143] W.D. Pilkey, L. Kitis and B.P. Wang, Optimal vibration reduction over a frequency range, Shock and Vibration Digest 14 (1982), 897-898.

[144] W.D. Pilkey and R.M. Little, A linear programming approach for balancing flexible rotors, J. Engineering for Industry 98 (1976), 1030-1035.

[145] W.D. Pilkey and T.W. Lim, Optimum shock isolation with minimum settling time, Shock and Vibration Bulletin 57(1) (1987), 379-388.

[146] W.D. Pilkey and M. Rosenstein, Shock spectra for classes of excitations, Shock and Vibration Bulletin 59(2) (1988), 171183.

[147] W.D. Pilkey, E. Sevin and A.J. Kalinowski, Computer aided design of optimum shock isolation systems, Shock and Vibration Bulletin 39(4) (1968), 185-198. 
[148] W.D. Pilkey and J. Strenkowski, Optimal Performance of Crashing Automobiles, Vehicle System Dynamics, Swets and Zeitinger (1974)

[149] W.D. Pilkey and B.P. Wang, A computer program to determine the limiting performance of physical systems subject to transient inputs, Shock and Vibration Bulletin 42(5) (1972), 185-190.

[150] W.D. Pilkey and B.P. Wang, Limiting performance of ground transportation vehicles subject to transient loading, AIAA Journal 12 (1974), 1011-1012.

[151] W.D. Pilkey and B.P. Wang, Limiting performance characteristics of randomly disturbed dynamic systems - a survey, Shock and Vibration Digest 7 (1975), 1-6.

[152] W.D. Pilkey and B.P. Wang, On the optimal location of vibration supports, Shock and Vibration Bulletin 52(5) (1982), $55-58$.

[153] W.D. Pilkey, B.P. Wang and L. Kitis, Optimal frequency response modification by added passive structures, J. Aircraft 20 (1983), 897-898

[154] W.D. Pilkey, B.P. Wang and D. Vannoy, Efficient optimal design of suspension systems for rotating shafts, J. Engineering for Industry 98 (1976), 1026-1029.

[155] R. Plunkett, The calculation of optimum concentrated damping for continuous systems, J. Applied Mechanics 25 (1958), 219-224.

[156] R. Plunkett, Vibration response of linear damped complex systems, J. Applied Mechanics 30 (1963), 70-74.

[157] L.S. Pontryagin, V.G. Boltyanskii, R.V. Gamkrelidze and E.F. Mishchenko, Mathematical Theory of Optimal Processes, Wiley-Interscience, New York, 1962.

[158] B. Porter, Synthesis of optimal suspension systems, Engineer 223 (1957), 619-622.

[159] V.A. Prourzin, Optimum shock isolation of a round device, Izv. AN SSSR. Mekhanika Tverdogo Tela (Mechanics of Solids), No. 2 (1988), 32-37 (in Russian).

[160] V.A. Radzievskii, Problem of the errors and optimum damping in the single component vibration measuring apparatus of the seismic type, Dopov. Akad. Nauk UkrSSR 5 (1956), p. 426.

[161] S.S. Rao and S.K. Hati, Optimum design of shock and vibration isolation systems using game theory, Engineering Optimization 4 (1980), 215-226.

[162] B.P. Robertson and W.D. Pilkey, Limiting performance for the control of large vibrating structures by a modal approach, $A n$ alytical and Experimental Modal Analysis 2 (1986).

[163] R.E. Robertson, Synthesis of a non-linear dynamic vibration absorber, J. Franklin Institute 254 (1952), 205-230.

[164] J.E. Ruzicka, Characteristics of mechanical vibration and shock, J. Sound and Vibration 1 (1967), 14-21.

[165] J.E. Ruzicka, Active vibration and shock isolation. SAE 680747, 1968

[166] J.E. Ruzicka, Passive shock isolation, Pt. I, J. Sound and Vibration 4(8) (1970), 14-24.

[167] J.E. Ruzicka, Passive shock isolation, Pt. II, J. Sound and Vibration 4(9) (1970), 10-22.

[168] V.M. Ryaboy, Minimum mass of elastic-inertial vibration isolation systems, Izv. AN SSSR. Mekhanika Tverdogo Tela (Mechanics of Solids), No. 4 (1980), 41-48 (in Russian).
[169] V.M. Ryaboy, Limiting capabilities of elastic-inertial vibration protection systems, Izv. AN SSSR. Mekhanika Tverdogo Tela (Mechanics of Solids), No. 5 (1982), 37-44 (in Russian).

[170] V.M. Ryaboy, Construction of dynamic diagrams and determination of the parameters of vibration isolating systems with given properties, Soviet Machine Science 5 (1985), 37-43 (in Russian).

[171] V.M. Ryaboy, Inverse problems and global optimization of the oscillatory systems, in: Proc. IUTAM Symposium on Dynamical Problems of Rigid-Elastic Systems and Structures, Springer, Berlin, 1991, pp. 205-214.

[172] V.M. Ryaboy, Limit of effectiveness of elastic-inertial vibration-isolating systems below and above resonance, Izv. AN SSSR. Mekhanika Tverdogo Tela (Mechanics of Solids), No. 1 (1993), 39-47 (in Russian).

[173] V.M. Ryaboy, Limiting performance and optimal synthesis of multi-body vibration isolation systems, Proc. International Noise and Vibration Control Conference "Noise-93", Vol. 7, St. Petersburg, 1993, pp. 95-102.

[174] V.M. Ryaboy, Limiting performance and optimal synthesis of the vibration isolating structures, in: Proc. 5th International Conference on Recent Advances in Structural Dynamics, Institute of Sound and Vibration Research, Southampton, UK, 1994, pp. 681-698.

[175] V.M. Ryaboy, Limiting performance estimates for the active isolation in multi-degree-of-freedom mechanical systems, J. Sound and Vibration 186 (1995), 1-21.

[176] V.M. Ryaboy, Shock isolation by a low-damped multi-degreeof-freedom mechanical system, J. Sound and Vibration 197 (1996), 381-385.

[177] Y.P. Samsonov, On the calculation of combined protection against vibration and shock disturbances, Trudy Moskovskogo Energeticheskogo Instituta 184 (1974) (in Russian).

[178] V.G. Saranchuk, A vibrational problem in game setting, Izv. AN SSSR. Mekhanika Tverdogo Tela (Mechanics of Solids), No. 1 (1974), 176-183 (in Russian).

[179] V.G. Saranchuk and V.A. Troitskii, Vibration isolation devices with minimum rattlespace, Trudy LPI (Leningradskii Politekhnicheskii Institut) Mekhanika i Protsessy Upravleniya. Vychislitel'naya Matematika, No. 307 (1969), 39-46 (in Russian).

[180] V.G. Saranchuk and V.A. Troitskii, On the synthesis of optimal isolators, Trudy LPI (Leningradskii Politekhnicheskii Institut) Mekhanika i Protsessy Upravleniya. Vychislitel'naya Matematika, No. 318 (1971), 43-49 (in Russian).

[181] A. Schlesinger, Vibroisolation in the presence of coulomb friction, J. Sound and Vibration 63 (1979), 213-224.

[182] L.A. Schmidt and R.L. Fox, Synthesis of a simple shock isolator. NASA, CR-55, 1964

[183] L.A. Schmidt and E.F. Rybicki, Simple shock isolator synthesis with bilinear stiffness and variable damping. NASA, CR64-710, 1965.

[184] A. Sereg and L. Howard, An approximate normal mode method for damped lumped parameter systems, J. Engineering for Industry 89 (1967), 597-604.

[185] E. Sevin, Min-max solutions for the linear mass-spring system, J. Applied Mechanics 24 (1957), 131-136. 
[186] E. Sevin, Automated design parameter identification. A new approach, J. Engineering for Industry 94 (1972), 388-394.

[187] E. Sevin and W.D. Pilkey, Computational approaches to the minmax response of dynamic systems with incompletely prescribed input functions, J. Applied Mechanics 34 (1967), 8790.

[188] E. Sevin and W.D. Pilkey, Min-max response problems of dynamic systems and computational solution techniques, Shock and Vibration Bulletin 36(5) (1967), 69-76.

[189] E. Sevin and W.D. Pilkey, Optimum Shock and Vibration Isolation, Shock and Vibration Information Analysis Center, Washington, DC, 1971.

[190] L.I. Shatrovskii, On a numerical method for solving optimal control problems, Zhurnal Vychislitel'noi Matematiki i Matematicheskoi Fiziki 2(3) (1962), 488 (in Russian).

[191] I.R. Silina, Numerical method for solving a minimax problem of control theory, Vestnik LGU (Leningradskii Gosudarstvennyi Universitet). Matematika, Mekhanika i Astronomiya, No. 7, Issue 2 (1976), 76-81 (in Russian).

[192] J.F. Springfield and J.P. Raney, Experimental investigation of optimum end supports for a vibrating beam, Experimental Mechanics 2 (1962), 366-372.

[193] R.B. Statnikov and J.B. Matusov, Multicriteria Optimization and Engineering, Chapman \& Hall, New York, 1995.

[194] B.F. Stone, Optimization of vibration absorbers: iterative methods for use on systems with experimentally determined characteristics, J. Mechanical Engineering Science 9 (1967), 382-392.

[195] I.R. Timoshina and I.R. Shablinskaya, Method of solving one non-smooth problem on the basis of the integral necessary condition of extremum, Vestnik LGU (Leningradskii Gosudarstvennyi Universitet), Matematika, Mekhanika i Astronomiya, No. 7, Issue 2 (1980), 47-51.

[196] A.K. Trikha and D.C. Karnopp, A new criterion for optimizing linear vibration isolator systems subject to random input, J. Engineering for Industry 91 (1969), 1005-1010.

[197] V.A. Troitskii, On the synthesis of optimal shock isolators, Prikladnaya Matematika i Mekhanika 31(4) (1967), 624-630. In English: J. Applied Mathematics and Mechanics 31 (1967), 649-654.

[198] V.A. Troitskii, Optimal Oscillatory Processes in Mechanical Systems, Mashinostroenie, Leningrad, 1976.

[199] P. Vausherk and J. Peters, Optimization of dynamic shock absorption for machinery, CIRP Ann. 12 (1963), 120-126.
[200] E.D. Viktorov and R.M. Larin, Some features of the problem of the minimum control of the maximum deviation, Izv. AN SSSR. Mekhanika Tverdogo Tela. Inzhenerniy Zhurnal (Mechanics of Solids), No. 4 (1967), 68-71 (in Russian).

[201] E.D. Viktorov and R.M. Larin, Method of gradually improving control functions in the problem of optimal isolation, Trudy LPI (Leningradskii Politekhnicheskii Institut), Mekhanika i Protsessy Upravleniya. Vychislitel'naya Matematika 307 (1969), 136-143 (in Russian).

[202] T.K. Vinogradova, Some minmax problems of optimal control . Ph.D. thesis (physics and mathematics), Leningrad State University, Leningrad, (in Russian).

[203] T.K. Vinogradova and V.F. Demyanov, On the minmax principle in optimal control problems, Doklady AN SSSR 213(3) (1973), 512-514 (in Russian).

[204] T.K. Vinogradova and V.F. Demyanov, On the necessary conditions in minmax control problems, Zhurnal Vychislitel'noi Matematiki i Matematicheskoi Fiziki 14(1) (1974), 233-236 (in Russian).

[205] B.P. Wang, Limiting performance of mechanical systems subject to steady state excitation. Ph.D. dissertation, University of Virginia, 1979.

[206] B.P. Wang and W.D. Pilkey, On the optimal location of vibration supports, Shock and Vibration Bulletin 52(5) (1982), $55-58$.

[207] B.P. Wang and W.D. Pilkey, Limiting performance characteristics of steady-state systems, J. Applied Mechanics $\mathbf{4 2}$ (1975), 721-726.

[208] B.P. Wang, L. Kitis, W.D. Pilkey and A. Palazzolo, Synthesis of dynamic vibration absorbers, J. Vibrations, Acoustics, Stress, and Reliability in Design 107 (1985), 161-166.

[209] K.P. White, W.D. Pilkey, H.C. Gabler and T. Hollowell, Optimizing design parameters for highway vehicle safety, International J. Vehicle Design, 4 (1983), 618-632.

[210] D.J. Wilde, Optimum Seeking Methods, Prentice-Hall, Inc., Englewood Cliffs, NJ, 1964.

[211] K.D. Wilmert and R.L. Fox, Optimum design of a linear multi-degree-of-freedom shock isolation system, J. Engineering for Industry 94 (1972), 465-471.

[212] J. Wolkovich, Techniques for optimizing the response of mechanical systems to shock and vibration, SAE 680748, 1968. 

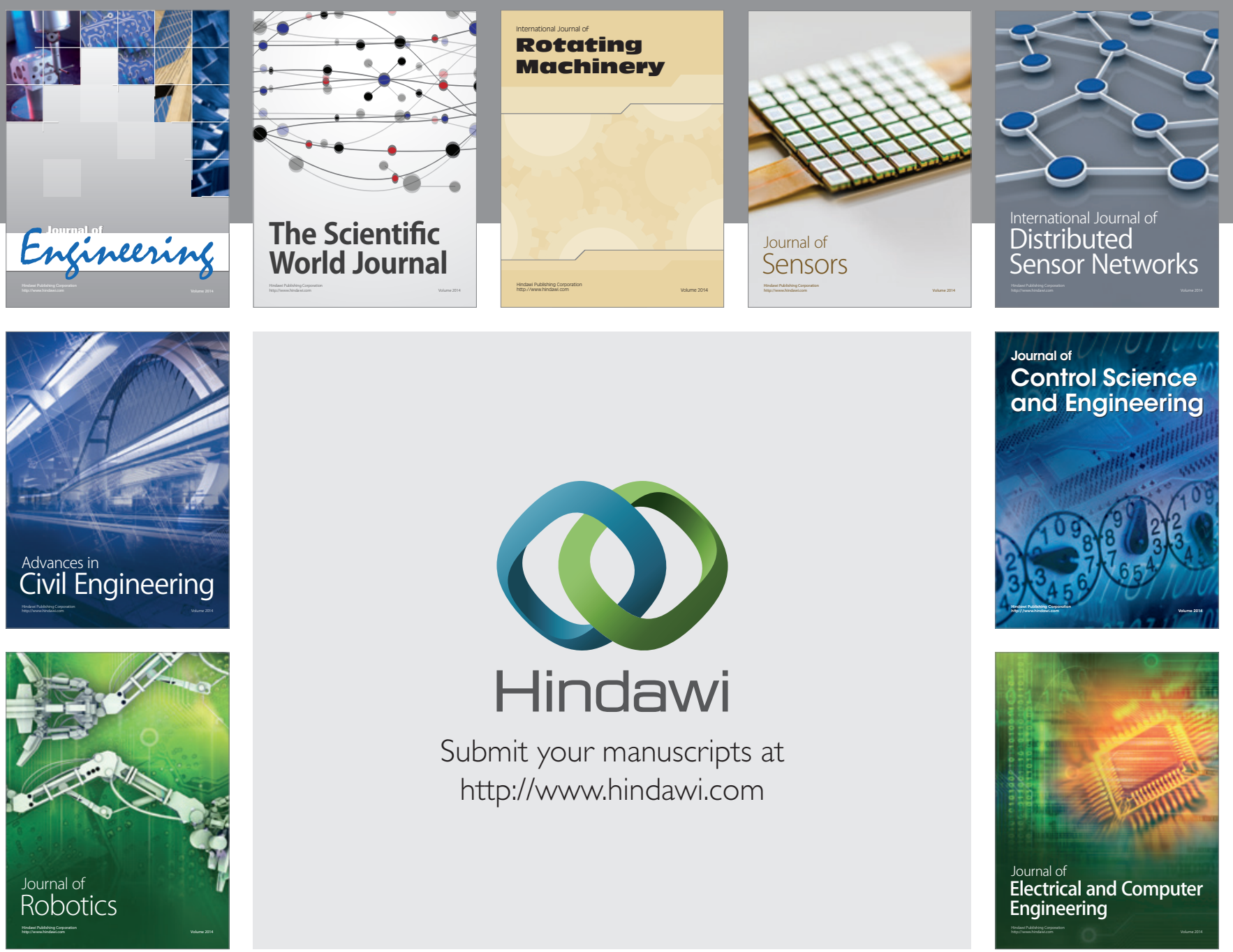

Submit your manuscripts at

http://www.hindawi.com
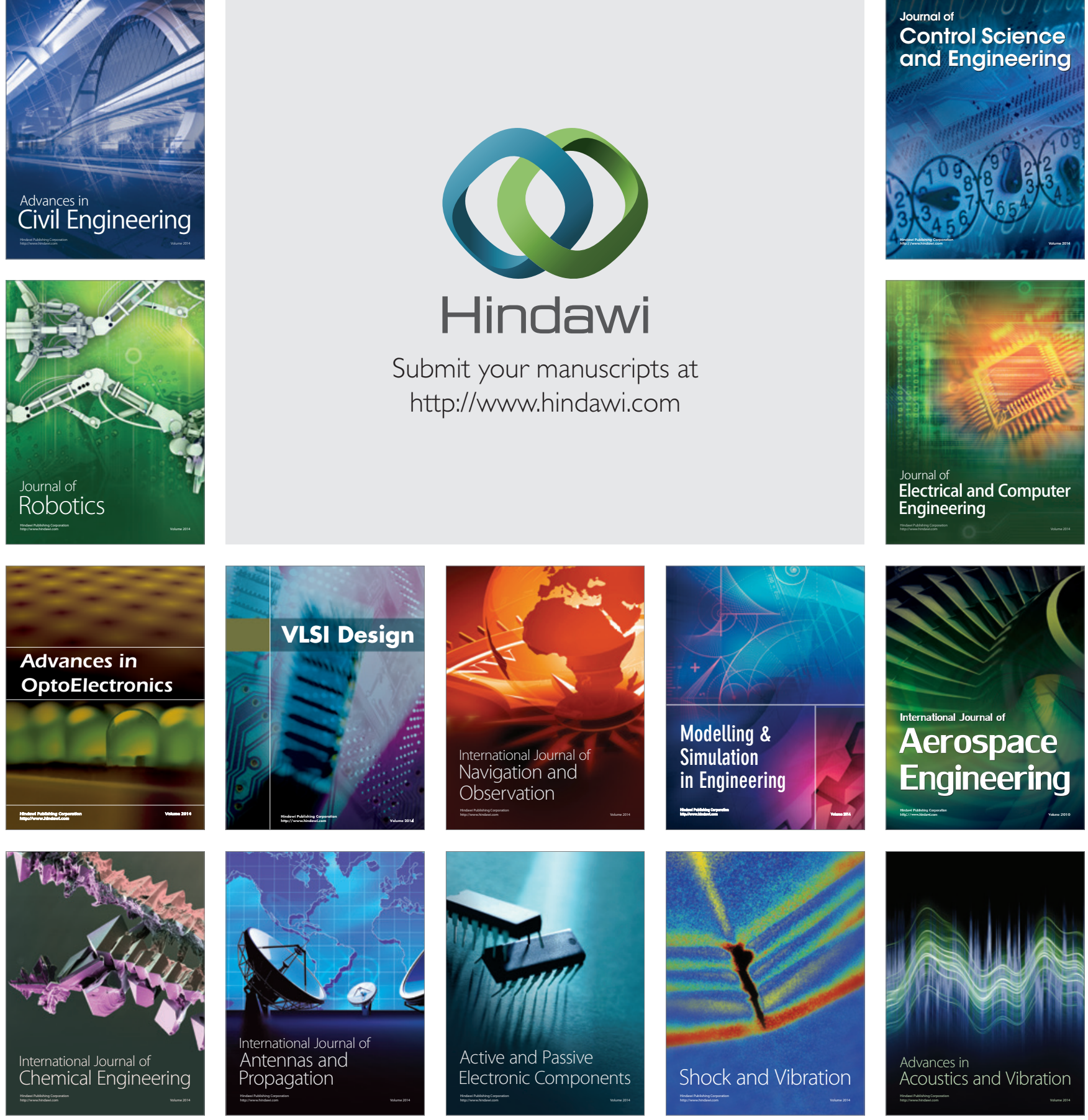